\title{
Entrevista com Maria Lúcia Raymundo
}

\section{A Necessidade de Criar}

Necessidade de criar é como uma necessidade de sobrevivência, de se sentir vivo, já que a gente está numa civilização ocidental, que nos manda assim, a todo o momento. $E$ também é uma busca de identidade. $E$ a busca de identidade é uma forma de sentir.

Eu acho que as pessoas escolhem profissões ou são escolhidas por profissões. É uma espécie de campo de batalha. Todos nós escolhemos um campo de batalha conosco mesmo. E aí, no caso, o ator escolhe o teatro como campo de batalha.

\section{A Profissão que Escolhe}

Eu queria ser jornalista e aí não foi possível fazer o vestibular naquele momento. Então fiz o vestibular para filosofia; daí, eu não me vi como professora de filosofia e muito menos escrevendo trabalhos filosóficos. Porque sou muito prática, das coisas da ação e tal. Mas eu tive a sorte de ser aluna do Gerd Borheim, meu professor de filosofia durante quatro anos. E, certa vez, nós discutimos sobre filosofia do teatro, e eu gostava muito desse assunto e perguntava muito pra ele. Aí, ele disse assim: "Vai lá no DAD que tem um curso livre de teoria teatral. Tu não precisas nem se matricular para o curso, é aberto ao público". Naquele tempo ele era o diretor do DAD e ministrou aulas neste curso. Eu comecei a freqüentar e a gostar muito. Todas as matérias teóricas, as mesmas que os alunos do DAD faziam, o público podia assistir. Acontece que a história faz as coisas também. No ano de 1969 houve um expurgo dos professores do DAD. Foi quando eu estava fazendo este curso. E os alunos criaram um movimento, porque sempre era o boato que iam fechar a escola e aquela perseguição e aquela paranóia que a gente tinha. E tudo era realmente muito forte, muito perigoso. E nós começamos a inventar coisas para fazer, para manter a escola aberta. E o que seriam essas coisas? Manifestos e discursos, não. Cenas! Cenas e cenas e cenas eram produzidas diariamente. E 
nós abrimos os portões para que o público entrasse gratuitamente e a escola tivesse movimento. E aí o fechamento da escola ia ter uma repercussão junto ao público muito maior. Como eu não era da prática de palco, mas me dava bem com ao atores e diretores da escola, eles me disseram: "Tu vens para cena". Foi assim que entrei no teatro. Fui escolhida pelo teatro, literalmente.

\section{A Função Social do Ator, Sua Identidade Pessoal e Profissional}

$\mathrm{Na}$ arte, os valores são sempre os mesmos. Tu pegas qualquer século, eles estão lá, universais dentro dos valores da humanidade, de ética, de estética, e uma coisa vai junto com a outra... Mas alguns valores, em determinado momento histórico, estão mais em foco e outros menos, depois muda. Estão sempre assim, nesta dança. E naquela época quando estava estudando no DAD, estes valores de protesto, de teatro explicitamente político tinha tudo a ver com o contexto histórico, com o momento cultural: as pessoas eram presas, perseguida e tudo o mais que tu já sabes.

Hoje eu acho, eu continuo achando, que o ator, na formação dele, se é esse seu campo de batalha mesmo, se é uma forma de autoconhecimento, não há como não se envolver, não interpretativamente, como técnica artística, teatral, estática do teatro ou de linguagem... Se ele trabalha sobre ele mesmo, ele está desenvolvendo uma ética, mesmo que ele não se dê conta, entende? Se ele está em cena, inteiro, vulnerável, um ser humano inteiro, ele está dizendo assim: "Estou aqui na frente de vocês, entende, eu vou propor um trabalho. E eu não tenho armadilhas... Não sou diferente de vocês e eu vou tomar riscos aqui na frente de vocês. E estou trabalhando sobre um tema em que eu acho que vai ajudar as pessoas a pensarem mais sobre a convivência, a tolerância, as diferenças, o mundo social todo que a gente vive". Se ele conseguir que alguma pessoa do público saia desse trabalho que ele mostra pensando - nem é pensando - se colocando questões que se ela não tivesse visto este trabalho jamais se colocaria, ele está fazendo um trabalho social muito forte. Pode ser em qualquer nível: "Ah, teatro também pode ser feito assim? Eu gostei tanto dessa maneira!" Pronto! Já essa cabeça desse espectador está trabalhando: "Ah, essa idéia quer dizer que as coisas são mais 
complexas, que não existe só o preto e o branco; a convivência humana é complexa; a diferença, o respeito, a interdependência dos seres humanos entre si é assim? Pronto: o ator fez um trabalho social, mesmo que não fique no palco gritando slogans.

\section{O Desenvolvimento da Imaginação Criadora}

Eu acho que nunca pensei muito nisso. Eu acho que o trabalho do ator, o trabalho da arte, qualquer um, o trabalho nesta área, do inefável, do que tu não tens controle sobre, ele é sempre um trabalho que se dá via indireta. Ele é sempre um caminho. Por exemplo: se tu tens uma proposta de trabalho, tu como bailarina, atriz, tu não vais andar de A a B numa linha reta. Até podes, mas o trabalho certamente vai ficar muito pobre: em imaginação, em possibilidades criativas, de linguagem, de como vais abordar o tema que tu queres. Para mim ele é no mínimo uma elipse e nessa volta tu acabas descobrindo coisas que vão te revelar muito mais à idéia primeira, vamos dizer que tu tiveste.

Então eu nunca me preocupei assim com imaginação, porque o que mais me satisfaz me dava prazer e continua me dando, no trabalho de atriz é o jogo. E o jogo é indispensável.

Eu sempre conto para os alunos uma história, uma lenda, não sei é verdade, a respeito do Garcia Marquez, que ele era jornalista, jovem, mas antes disso mesmo, ele morava em uma cidade do interior da Colômbia, e ele era adolescente e foi pela primeira vez ao cinema. E viu um filme de Charles Chaplin. E saiu deslumbrado, fascinado e pensando assim: "Se isso vale, as história da minha vó também valem". Então era mais ou menos isso, de não aceitar que eu tinha que achar uma coisa teatral para fazer no palco, tudo 0 que vinha intuitivamente rolava. Uma vez eu fiz a Koullina, que era uma criada. Então, para brincar com aquela demora, que os atores se acertassem, cada vez que a Koullina tinha que entrar, eu jogava, eu brincava para eu mesma me divertir, para passar o tempo. E resultava que todo mundo dizia: "A única coisa que funciona é a Maria Lúcia fazendo a Koullina. E eu dizia assim: "Mas eu não 
fiz nada!" Tu me entendes? Eu não me dava conta de que aquele jogo era... por que era sem a intenção de fazer, ele resultava numa coisa inteira.

Eu acho que esse processo de imaginação é uma comunicação direta contigo mesmo e com o público. Vem uma idéia, uma imagem, tu lanças, tu ages e essa ação vai te dizer imediatamente o que tu vais fazer depois. Claro que, paralelo a isso, tem uma coerência que não quer dizer sempre uma clareza muito imediata e muito explícita, entende, e didática no mau sentido (de preocupação com essa clareza). Mas tem uma coerência, uma linha nesse jogo de personagem que dá consistência, que dá solidez, porque ele mesmo praticamente se resolve. Como aquilo que eu digo para os alunos sempre: "Há algo em você que sabe mais do que você. E,quando tu confias nesse algo, expõe tudo mais claro; tudo aquilo que tu vês o ator pensando e decidindo, aí é frágil e não é crível, não verdadeiro." É esse aprendizado assim: "para não deixar dúvidas que tu tens um enorme prazer de se lançar no abismo, e que lá tem alguma coisa".

\section{O Jogo Pode Ser...}

...com o espaço, com o tempo, com o companheiro, com a própria imaginação, coma memória (a memória pode se tornar um espaço mental), com qualquer tema ou ponto de referência que tu queiras jogar, com o corpo em movimento, com o próprio movimento tu podes fazer um jogo que faz sentido, que tem uma narrativa, que as pessoas compreendem.

\section{Personagem}

O personagem sempre foi muito trabalhado assim, ó: não ficava lendo muito o texto, muito menos decorando, entende? Era sempre sobre uma idéia, uma referência, uma espécie de contato, uma porta de entrada de contato, uma afinidade ou uma não-afinidade: uma coisa que tu jamais pensarias como aquele personagem, também é uma porta de entrada... Afrontar o personagem também funciona. E, através de improvisações, ir achando esses caminhos sempre pelo desconhecido, sempre pelo que tu não sabes.

Aquele (personagem) está no papel, aí tu te aproximas muito dele, mas, de qualquer maneira, tens que fazer a tua interpretação. 
Claro, porque senão tu vais fazer um personagem que geralmente fica muito literário, muito baseado no texto, nas rubricas do autor, e fica muito chapado. Ele não tem profundidade, ele não tem volume, ele não tem história anterior e posterior àquela que está na peça. Então, claro que eu aproximo, eu falo o texto como está escrito, mas isso é depois que ele está pronto, que ele está vivo, que ele pode reagir a qualquer improvisação que não está no texto.

Por exemplo: tu estás me dirigindo na Longa Jornada e tu imaginas uma situação de ensaio, que não está no texto. Tu fazes comigo, tu entendes? E essa coisa, a coerência está no texto, vai estar nesta improvisação, ou desta improvisação posso achar mais coerência para as falas...

$\mathrm{Na}$ improvisação, gosto muito assim: eu avanço muito, entende? Eu arrisco muito, a coisa tem que ir para frente. Como professora e como aluna, eu detestava aquelas improvisações que ficavam em volta: que não acontece nada, fica todo mundo falando e daí, e daí, e daí... e não avança a história, não avança a narrativa. As coisas que têm importância são as coisas fortes que vão aparecer. Parece que os atores têm um pouco de medo de chegar nesses momentos assim cruciais, e eu adoro!

$\mathrm{Na}$ verdade, eu acho que interpretar é transpor de uma linguagem para a outra. Em todas as profissões é assim: tu podes pegar um cientista, ele interpreta a linguagem da natureza, com a linguagem da ciência; tu pegas um desenhista, um pintor, a linguagem da natureza ou da imaginação, dos sonhos, para uma linguagem pictórica ou plástica. Tu pegas a linguagem literária de um personagem, que é do texto, para a linguagem mímica, da ação, tu transpõe.

Eu acho que dá muito medo, dá muita insegurança, tu podes te arriscar. Eu nunca fui uma pessoas que tivesse problema de me arriscar... Esse medo do ridículo. Passei cada bobagem! E eu já sei que vou fazer outra coisa de novo e aí vai ser legal.

Aqui, por exemplo, aquele espetáculo que fiz com a Maria Helena Lopes, foi a Crônica, nós não temos o texto escrito até hoje! Tinham temas, idéias, autores literários que não eram teatrais, que era o Eduardo Galeano, que era o Garcia Marquez, que era o Lorca, que era um pouco de cada coisa de um universo. A Maria Helena propunha situações. Muitos atores fizeram muitos personagens, daí alguns daqueles personagens foram ficando com aqueles 
atores, que foram conquistando, se apossando deles ou vice-versa, a gente nunca sabe... E era uma delícia! E naquelas improvisações eu me jogava! É um prazer tão grande para mim esse jogo de imaginar, de criar, de inventar uma pessoa que não existe e que acaba existindo! E muitas improvisações não davam certo, mas eu dava risada e ia de novo. A capacidade de rir de ti mesmo, de não se levar tão à sério, não achar que é um ator, assim,que vai resolver tudo na primeira.

Então, tem essas duas maneiras: o texto e essa forma de abordar o personagem, de inventar um personagem que não existe, que tem nome, história, comportamento, ações,mundo anterior, tudo...

\section{O Jogo}

O jogo é uma maneira de libertar o ator. Na verdade, o difícil não é ser ator. Eu digo para os meus alunos: "Tem muita gente aí com diploma de ator, ou que se produz e que se diz ator, , e que não devia, que não teria direito de estar no palco, mas estão, entende?O difícil, então, não é ser ator, é ser inteiro, orgânico, verdadeiro, aquele ator que sabe dar um tipo de emoção que só ele sabe dar para o espectador, entende? E a nossa vida é perseguir essa coisa em cena. $O$ jogo possibilita muito para 0 ator, vamos dizer,iniciante, principiante, jogar sem compromisso.Quando ele vê, está inteiro, porque ele está acreditando no jogo. $O$ inteiro é acreditar no que tu fazes concretamente.

Mas não é só com o jogo que tu pode sabor dar um trabalho. Agora, por exemplo, tem outras maneiras: tem as seqüências, tem as partituras, tem os fragmentos. Tudo isso pode ser uma maneira de abordar o personagem. Mas esse estado de organicidade, de estar inteiro, tem que estar presente, seja no jogo, seja na partitura, seja no fragmento, seja no decorar o texto e sair dando a fala.

Para encontrar esse caminho, na verdade, penso assim: tu crias, tu te trabalhas, tu trabalhas primeiro para ter controle sobre ti, o teu corpo, a tua voz, a tua presença, o espaço, o tempo. Depois, tu trabalhas ainda mais para ter precisão, além do controle, com mais requinte ainda. A precisão: tu fazeres 0 que tu queres contigo, ir além, além, além. E esse trabalho sobre ti mesmo, como é que vou dizer... é a única forma de criar condições para que o teatro 
aconteça em ti. Na verdade, tu não fazes o teatro pela tua vontade, entende? "Porque eu quero!" Aí seria muito fácil, todo mundo seria brilhante. O negócio é tu criares condições para que ele aconteça em ti de uma maneira excelente, eficaz, para que possa comunicar. Se tu crias condições como atriz, ele vai acontecer! Sempre pela via indireta: é abrir o espaço, abrir o vazio, não tomar decisões, principalmente mentais e racionais, não é pela tua vontade. Tu não tens controle sobre isso. Tu crias condições e tu te entregas, esperas e jogas, feliz ou angustiada.

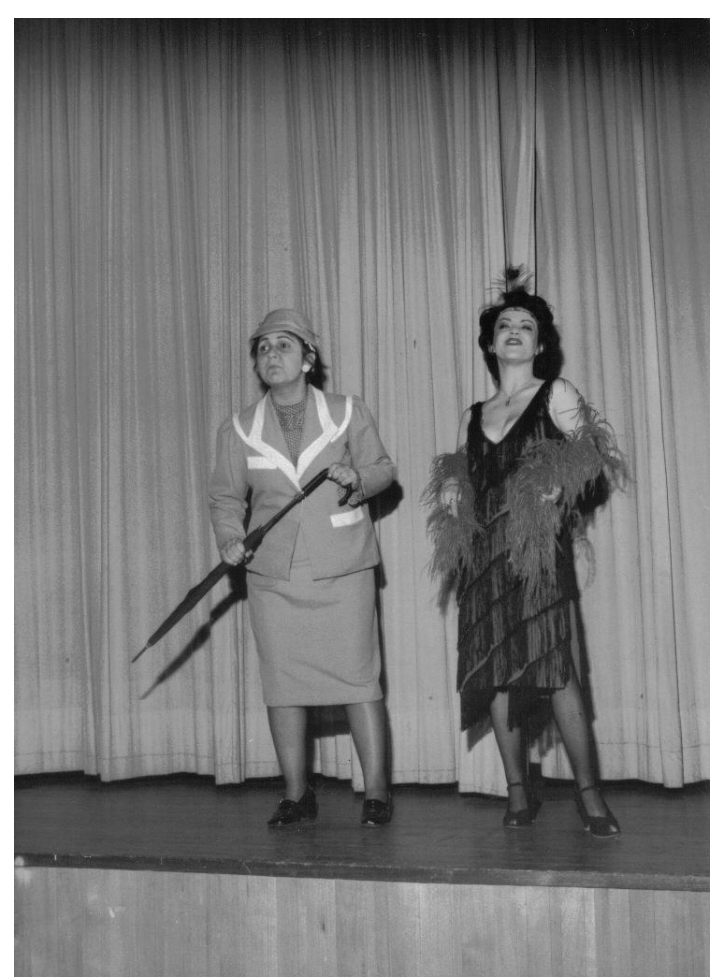

\section{A Preparação do Ator}

Essa preparação, ela é sempre uma descoberta. Porque é um caminho individual sempre. E há muitos motivos para a gente estar no teatro, como diz o Eugênio Barba: compensações pessoais, por queremos ser super star... $E$ todos são legítimos, desde que a pessoa saiba por que ela quer fazer. E há muitas maneiras...

Eu participei de uma ISTA, lá em Londrina, cujo tema era tradição e fundadores de tradição. Então pediram para escrever a nossa tradição pessoal de formação de ator. 
Comparado com os atores orientais, tu imaginas a nossa tradição: uma salada! A minha formação era uma salada tão grande, que foi lida no ISTA como exemplo, para fechar todas as coisas. Para ver que a tradição ocidental é assim! Nós temos que assumir isso. E assim, funciona! E funciona porque a nossa história é assim!

Eu fiz a formação no DAD (Departamento de Arte Dramática - UFRGS) com a Maria Helena Lopes, que vinha com a linha do Eugênio Kusnet, foi como - Stanislavski chegou no Brasil. Fiz formação com Patrícia Stokoe, na Argentina, durante vários anos.

Também fiz formação na iniciação de Laban, Barteniev, toda questão do movimento. Fiz formação nos Estados Unidos com outras linhas, inclusive com Sudake, que era um estilo de teatro oriental, teatro acting. Fiz formação na França com o Jean-Paul Denison, na linha do Peter Brook, que ele é ator e assistente do Brook. Fiz curso com ele, com o Barba, fiz com ex-alunos do Grotovski.

Agora vocês, os jovens atores, quanta coisa está chegando em Porto Alegre, quanta oficina, quanta informação, quanto workshop? Mas aí tem uma questão muito delicada e é muito forte, tanto na escola quanto fora, que é a questão do ator organizar os seus saberes. Porque não adianta fazer um monte de workshops se tu não traças, não organizas estes teus saberes de uma forma que ele vai ser produtivo para ti, que tu não fiques sempre começando do zero. Tu fazes um curso e tu não absorves, tu não te encharcas daquilo para dizer: eu tenho essa formação, eu sei fazer isso como atriz, hoje eu posso fazer, eu posso repetir, eu conquistei isso, esse é o meu trabalho como atriz. Eu acho que mais do que buscar técnica é aprender: primeiro, eu tenho que dar conta de organizar os meus saberes, de saber o que me serve, o que não me serve. Outra coisa: saber que eu estou trabalhando com uma linguagem, que essa linguagem tem uma leitura, que ela está sempre narrando, por mais hermética que ela seja, por mais fragmentada. Ela é uma linguagem, tu não podes fazer qualquer coisa e chamar de teatro. Eu não vejo teatro onde as pessoas vêem teatro. Porque é arte! Tem que ter uma técnica e tem que aplicar essa técnica a serviço de uma linguagem. 
Eu acho que essa preparação, cada um sabe. E os atores hoje... tem um teatro completamente "fisical theatre" que se volta bastante para a exigência de uma presença física e haja trabalho para isso. Então isso vai rebater aonde? Na maneira como ele vive o dia a dia. Porque, se ele ficar até a manhã bêbado, ele não vai Ter condições físicas que depois o diretor, o professor, vão pedir para ele. Isso vai rebater no tipo de alimentação, numa cultura física paralela com isso que eu falei, que ajuda para que eu mantenha corpo e mente para a arte, que não é o cotidiano, é o extra-cotidiano. Mas eu não saberia te dizer, porque eu acho que é uma conquista, também, que vem com o tempo e de cada ator. Essa descoberta é muito importante, porque também tem muito modismo para o jovem. Daí os jovens querem fazer o que está na moda, às vezes, aquele modismo para ele não funciona. Tudo tem que consultar muito o teu interior, mas isso tem que ter uma certa maturidade. Perguntar para 0 coração e dizer o que realmente eu me sinto bem fazendo.

\section{A Vida no Palco}

Essa coisa da vida no palco é porque é assim. Nós temos que ter um certo consenso social, cultural, histórico para sobreviver. Então, tem os limites da vida comunitária: comportamentos, normas, regras, até para expressão das nossas emoções. Tudo é regrado pelo nosso convívio social, que é uma forma de sobrevivência. Na arte, essas regras, elas se diluem. Aliás, a arte se faz necessária desde a pré-história, essa manifestação simbólica, de linguagem simbólica da espécie, por causa disso: porque é uma via para não enlouquecer. Então lá no palco tudo é real porque tudo é possível: todos os problemas podem ser tocados, as cavernas mais obscuras, as zonas mais sombrias da condição humana, no palco, podem ser faladas. Mas aqui fora já é um risco, embora toda essa condição humana a gente carregue junto.

Tem um poeta americano, William Carlos William, que tem um poema muito lindo que diz que a imaginação não cessa jamais, jamais, nunca. E aí ele diz em uma parte do poema que tudo o que não vira arte, vira crime, que essa imaginação não para nunca. É por isso que a gente tem que chamar as pessoas para arte, para não deixar que essa imaginação vire crime. 
Eu acho agora, tanto a psicanálise e a arte, quanto à espiritualidade, são uma coisa só, são partes de uma mesma saída para humanidade, que o ator pode encontrar, que o artista... E $\mathrm{O}$ ator ainda mais, porque ele tem que trabalhar consigo, com uma substância humana que tem que virar dramática e que tem que virar linguagem. Ele tem que estar sempre num outro mundo, num mundo do além. A gente tem essa coisa de ir visitar esse país do mistério e voltar. E ninguém visita esse país de mistério impunemente. Alguma coisa acontece no teu interior, na tua espiritualidade. Alguma coisa muito boa acontece contigo, e que é a força da nossa arte. O Decroux dizia para seus atores, quando ele começava a trabalhar, uma das maneiras de criticar: "Humano, humano demais!" Nós temos quase que ir ao inhumano, tudo o que tu quizeres chamar, porque humano demais para ele não servia. $E$ é isso, essa viagem, quer dizer, o que tu tens em experiência de inteireza.

Eu faço um trabalho que em me encontrei muito, que é uma abordagem do trabalho do ator, que é biocultural ou neurocultural, que vai pela neurociência, que tem muito a ver com os caminhos do budismo: essa entrega, que é essa ida ao desconhecido, saber que tu não tens controle de nada, que se tu quiseres que alguma coisa grande aconteça contigo, tu tens que te entregar. Entregar-se dessa forma, alguma coisa acontece. Tem uma citação muito linda de São Francisco de Assis que serve muito para o ator, essa preparação, essa abordagem de personagem, que é assim: "Para ir aonde tu não sabes, vai por onde tu não sabes"...

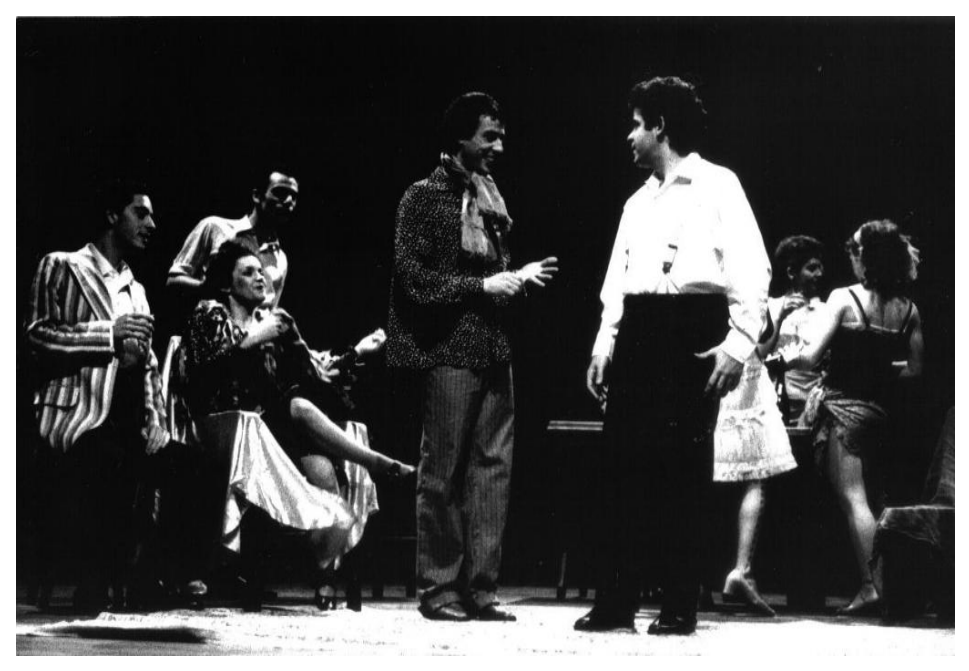


E serve para nós, assim, perfeito. Para criar realmente o personagem que é teu, a tua autoria tem que ir pelo caminho que não sabes. Se tu vais pelo caminho que tu tens, que tu já trilhaste e sabes que por ali funcionou, tu vais chegar aonde tu já sabes. 